\title{
BMI-mortality association: shape independent of smoking status but different for chronic lung disease and lung cancer
}

This article was published in the following Dove Press journal: International Journal of COPD

\author{
David Faeh ${ }^{1,2}$ \\ Marco Kaufmann' \\ Sarah R Haile' \\ Matthias Bopp' \\ On behalf of the Swiss \\ National Cohort Study \\ Group
}

'Epidemiology, Biostatistics and Prevention Institute (EBPI), University of Zurich, Zurich, Switzerland; ${ }^{2}$ Health Department - Nutrition and Dietetics, Bern University of Applied Sciences, Bern, Switzerland
Correspondence: Matthias Bopp Epidemiology, Biostatistics and Prevention Institute (EBPI), University of Zurich, Hirschengraben 84, 800I Zurich, Switzerland

$\mathrm{Tel}+4|4463446| 4$

Fax +4I 446344986

Email matthias.bopp@uzh.ch
Background: Besides smoking, low or high body mass index (BMI) is associated with chronic lung disease (CLD). It is unclear how CLD is associated with BMI, whether smoking interacts with this association, and how the associations differ from the patterns known for lung cancer.

Population and Methods: Our population comprised 35,212 individuals aged 14-99, who participated in population-based surveys conducted in 1977-1993 in Switzerland (mortality follow-up until 2014). We categorized smokers into never, former, light, and heavy; and BMI into underweight, normal weight, overweight, and obese. Hazard ratios (HRs) were obtained with multivariable Cox proportional hazards models.

Results: CLD mortality was strongly associated with being underweight. This was mainly due to the effect in men (HR 5.04 [2.63-9.66]) and also prevailed in never smokers (HR 1.81 [1.11-3.00]). Obesity was also associated with CLD mortality (HR men: 1.37 [1.01-1.86], women: 1.39 [0.90-2.17]), but not with lung cancer mortality. In line with lung cancer, for CLD, the BMI-mortality association followed the same shape in all smoking categories, suggesting that this association was largely independent of smoking status.

Conclusion: The shape of the BMI-mortality association was inversely linear for lung cancer but followed a U-shape for CLD. Further research should examine the potentially protective effect of obesity on lung cancer occurrence and the possibly hazardous impact of underweight on CLD development.

Keywords: chronic lung disease, lung cancer, mortality, body mass index, underweight, obesity, smoking

\section{Introduction}

Worldwide, COPD was the third and lung cancer the fifth most common cause of death in 2010. ${ }^{1}$ While smoking clearly increases the risk of both diseases, ${ }^{1}$ the impact of body mass index (BMI) is unclear. For both diseases, higher BMI could be a protective rather than a risk factor, but results are conflicting. ${ }^{2-10}$ In underweight individuals, the association between low BMI and disease outcome may be confounded by smoking, because smoking may be more prevalent in underweight than in normal weight people..$^{7,8,11,12}$ Moreover, reversed causation may bias the BMI-disease association, because COPD and lung cancer can lead to weight loss. ${ }^{8}$ Therefore, smoking and BMI need to be jointly analyzed. In a general population sample from Switzerland, we aim to elaborate similarities and differences regarding associations of BMI and smoking with mortality from chronic lung disease $(\mathrm{CLD}=$ mainly $\mathrm{COPD})$ and lung cancer. 


\section{Materials and methods}

\section{Study population}

The study population consists of originally 35,914 individuals aged 14-99 years at baseline who participated in one of four different population-based studies conducted between 1977 and 1993: NRP 1A (National Research Program 1A, 1977-1979, $n=8,008$ ); SOMIPOPS (SOcioMedical Indicators for the POPulation of Switzerland, 1982, $n=4,104$ ); Swiss MONICA (MONItoring of trends and determinants in CArdiovascular disease, three waves: I, 1984-1986; II, 1988/1989; III, 1992/1993, n=9,940); and the first SHS (Swiss Health Survey, 1992/1993, n=13,862), for details, see the study by Roh et al. ${ }^{13}$ The studies were conducted according to the ethical guidelines of the Swiss Academy of Medical Sciences. Informed consent was only obtained for SHS 92/93. For the other studies, the use of written informed consent was not custom when they were conducted, and the ethics committee (Cantonal Ethics Committee of the Canton of Zurich, KEK-ZH) approved our study under these conditions. For details, see the study by Roh et al. ${ }^{13}$ Mortality follow-up until 2014 was obtained through anonymous record linkage with the Swiss National Cohort. ${ }^{13}$ After exclusion of 30 deceased foreign nationals with missing cause of death, 612 subjects who died of external causes, 1 subject with invalid entry date, and 59 subjects with missing smoking status, our study population comprised 35,212 participants with a median follow-up time of 22.3 years and a maximum of 37.9 years.

\section{Body mass index}

BMI was defined as weight $(\mathrm{kg})$ divided by the square of height $\left(\mathrm{m}^{2}\right)$. Subjects were classified: normal weight $\left(18.5 \leq\right.$ BMI $\left.<25.0 \mathrm{~kg} / \mathrm{m}^{2}\right)$, underweight $(\mathrm{BMI}<18.5$ $\left.\mathrm{kg} / \mathrm{m}^{2}\right)$, overweight $\left(25.0 \leq \mathrm{BMI}<30.0 \mathrm{~kg} / \mathrm{m}^{2}\right)$, and obese (BMI $\geq 30.0 \mathrm{~kg} / \mathrm{m}^{2}$ ).

\section{Smoking}

Only baseline information was available for smoking status. Smoking was categorized: never, former (reported having ever smoked for $>6$ months), current light ( $<20$ cigarettes a day), and current heavy ( $\geq 20)$.

\section{Covariates}

In the final model, we adjusted for age (years), sex, survey (NRP 1A, SOMIPOPS, MONICA I-III, SHS), years of education (number of years: 0-30), marital status (single, married, widowed, divorced), nationality (Swiss vs foreign), self-reported physical activity (four categories: daily, several times per week, once per week, and less), alcohol consumption (consumption the day before the interview: yes vs no), and a diet proxy ("regularly eating three main meals per day" and "eating fruits and vegetables at least once per day": yes or no). For all covariates, we used baseline information.

\section{End points}

In view of frequent misclassification ${ }^{14}$ and in order to capture all cases potentially related with harmful exposure/behavior, we merged COPD with additional respiratory causes of death into a broader category CLD. As a majority of CLD registrations in Swiss cause of death statistics concerns concomitant causes of death, we included all mentions of CLD. Of these 612 CLD deaths, CLD was mentioned as primary cause of death in 276 death certificates and in 336 as secondary (concomitant) cause. In the latter cases, cardiovascular diseases $(55 \%)$ were the most frequent primary causes mentioned, followed by cancer $(23 \%)$. Lung cancer was rarely mentioned as secondary cause of death ( 1 out of 276 deaths due to CLD), and the definition was, therefore, limited to primary cause of death. Deaths with lung cancer as primary cause and CLD as concomitant were classified as lung cancer. Deaths were coded according to the International Classification of Diseases (ICD-8 until the end of 1994, ICD-10 thereafter). CLD was defined as ICD-8 490-493, 502, 503, 506, 517; ICD-10 J40-J47, J68, J96.1, lung cancer as ICD-8 162; ICD-10 C33-C34.

\section{Statistical analysis}

Death rates were directly age-standardized using the World Health Organization World Standard Population (2000-2025). ${ }^{15}$ Testing the proportional hazards assumption, hazard ratios (HRs) for death due to CLD or lung cancer were calculated using Cox proportional hazards regression, where survival times were censored if an individual died because of any other cause of death or was lost to follow-up. We evaluated competing risks regression models,${ }^{16}$ where survival times were censored only due to loss of follow-up but considered competing if the cause of death was not CLD or lung cancer, respectively. The results of the two analysis strategies were essentially the same, so we have reported only results of the Cox proportional hazards models, which some authors (eg, Lau et $\mathrm{al}^{17}$ ) have suggested to be better at answering questions regarding etiology. Analyses were performed with the $\mathrm{R}$ programming language (version 3.3.2). 


\section{Results}

Baseline characteristics are shown in Table 1. Heavy smokers tended to be male and to be younger than subjects in other smoking categories. They were also less physically active and less likely to have a healthy diet or to be Swiss nationals. CLD-related death was lowest among never smokers (1.0\%), intermediate among former and light smokers $(2.3 \%$ and $2.0 \%)$, and highest among heavy smokers (3.1\%). However, $4.7 \%$ of heavy smokers died due to lung cancer compared to about $1.6 \%$ of former or light smokers and only $0.6 \%$ of never smokers. The age-standardized death rates were $10.18 / 1,000$ person-years for all causes combined, 0.66 for CLD, and 0.44 for lung cancer (crude: 11.81, 0.76, and 0.69, respectively).

As shown in Figure 1, after full adjustment for covariates, the shape of the association of BMI with CLD and lung cancer mortality was strikingly consistent in smoking status strata. The combined consideration of BMI and smoking categories suggests for lung cancer a quite linear inverse association with the lowest risk in the highest BMI category (obesity). In contrast, the relationship between BMI and CLD was U-shaped with similarly increased risks in the highest and the lowest BMI category and the lowest risk in normal weight individuals.

\section{Discussion}

In line with our results, there is a broad agreement regarding the linear inverse association of BMI with lung cancer risk. However, it remains unclear whether the relationship is causal or whether the association is due to reversed causation..$^{6-9}$ A study looking at changes in BMI showed that only recent ( 2 years ago) but not earlier (20 years ago) underweight was associated with increased lung cancer risk and that the strongest predictor for death was a decline in $\mathrm{BMI}^{8}$ In contrast to the BMI-lung cancer association, overweight was associated with a lower and obesity with a higher risk of CLD. This U-shaped (vs linear for lung cancer) relationship was also reported in a meta-analysis including more than 10 million individuals. ${ }^{10}$ This is at odds with other studies suggesting a lower or a similar risk of CLD among obese compared to normal weight subjects. ${ }^{2-5}$ Evidence for an increased CLD mortality risk associated with underweight

Table I Baseline characteristics of the study population

\begin{tabular}{|c|c|c|c|c|c|c|}
\hline Characteristic & Never & Former & Light & Heavy & Total & Missings $^{\mathbf{a}}$ \\
\hline Full dataset ${ }^{\mathrm{b}}(\%)$ & $17,028(47.4)$ & $6,576(18.3)$ & $7,127(19.8)$ & $5,123(14.3)$ & $35,854(100)$ & \\
\hline Analyzed observations, n (\%) & I6,727 (47.5) & $6,468(18.4)$ & 7,015 (19.9) & $5,002(14.2)$ & $35,212(100)$ & 702 \\
\hline Women, n (\%) & $\mathrm{II}, \mathrm{I} 24(66.5)$ & $2,377(36.8)$ & $3,44 I(49.0)$ & $\mathrm{I}, 685(33.7)$ & $18,627(52.9)$ & 0 \\
\hline Person-years & 382,060 & 140,390 & 166,768 & I I 2,246 & 801,464 & \\
\hline Years of follow-up, mean $\pm S D$ & $22.8 \pm 9.0$ & $21.7 \pm 8.9$ & $23.8 \pm 9.3$ & $22.4 \pm 9.1$ & $22.8 \pm 9.1$ & \\
\hline Age, mean $\pm S D$ & $47.0 \pm 16.6$ & $48.6 \pm 14.7$ & $42.2 \pm 14.7$ & $41.2 \pm 12.2$ & $45.5 \pm 15.6$ & 0 \\
\hline $\mathrm{BMI}$, mean $\pm \mathrm{SD}$ & $24.2 \pm 4.0$ & $25.0 \pm 4.0$ & $23.8 \pm 3.7$ & $24.3 \pm 3.8$ & $24.3 \pm 3.9$ & \\
\hline \multicolumn{7}{|l|}{ BMI categories (\%) } \\
\hline$<18.5$ & 637 (3.9) & $126(2.0)$ & $300(4.3)$ & $165(3.3)$ & $\mathrm{I}, 228(3.5)$ & 443 \\
\hline $18.5-25$ (ref) & $9,817(59.6)$ & $3,290(5 \mathrm{I} .4)$ & $4,31 I(62.0)$ & $2,887(58.2)$ & $20,305(58.4)$ & \\
\hline $25-30$ & $4,603(28.0)$ & $2,355(36.8)$ & I,927 (27.7) & I,565 (3I.6) & $10,450(30.1)$ & \\
\hline$>30$ & $\mathrm{I}, 400(8.5)$ & $630(9.8)$ & $412(5.9)$ & 344 (6.9) & $2,786(8.0)$ & \\
\hline \multicolumn{7}{|l|}{ Marital status (\%) } \\
\hline Married & $10,827(64.8)$ & 4,909 (75.9) & $4,516(64.4)$ & $3,176(63.5)$ & $23,428(66.6)$ & 16 \\
\hline Divorced & $809(4.8)$ & $413(6.4)$ & $507(7.2)$ & $549(11.0)$ & $2,278(6.5)$ & \\
\hline Single & $3,594(21.5)$ & $807(12.5)$ & I,7I2 (24.4) & $\mathrm{I}, \mathrm{I} 48(23.0)$ & $7,261(20.6)$ & \\
\hline Widowed & $1,490(8.9)$ & $337(5.2)$ & $275(3.9)$ & $127(2.5)$ & $2,229(6.3)$ & \\
\hline \multicolumn{7}{|l|}{ Other covariates } \\
\hline Alcohol use (\%) & $9,503(57.1)$ & $4,823(74.7)$ & $4,930(70.5)$ & $3,816(76.4)$ & $23,072(65.8)$ & 135 \\
\hline Healthy diet (\%) & $12,185(74.0)$ & $4,379(69.0)$ & $4,456(64.9)$ & $2,405(48.2)$ & $23,425(67.5)$ & 535 \\
\hline Years of education, mean \pm SD & $11.5 \pm 3.2$ & $12.3 \pm 3.3$ & $12.0 \pm 3.1$ & $11.8 \pm 3.1$ & $11.8 \pm 3.2$ & 584 \\
\hline Swiss (\%) & $14,223(85.0)$ & $5,4 \mid 8(83.8)$ & $5,693(8 I .2)$ & 3,938 (78.7) & $29,272(83.1)$ & 0 \\
\hline \multicolumn{7}{|l|}{ Mortality } \\
\hline All, n (\%) & $4,524(27.1)$ & I,89| (29.2) & I,69I (24.I) & I,359 (27.2) & 9,465 (26.9) & \\
\hline CLD, n (\%) & $164(1.0)$ & $150(2.3)$ & $142(2.0)$ & $156(3.1)$ & $612(1.7)$ & \\
\hline Lung cancer, n (\%) & $95(0.6)$ & 104 (I.6) & 121 (I.7) & $236(4.7)$ & $556(\mathrm{I} .6)$ & \\
\hline
\end{tabular}

Notes: ${ }^{a}$ The maximum number of missing values in an analysis was 2,027 (some individuals had missing values for multiple variables). ${ }^{\text {EExcluding }} 60$ study participants with missing information on smoking status.

Abbreviations: BMI, body mass index; CLD, chronic lung disease. 

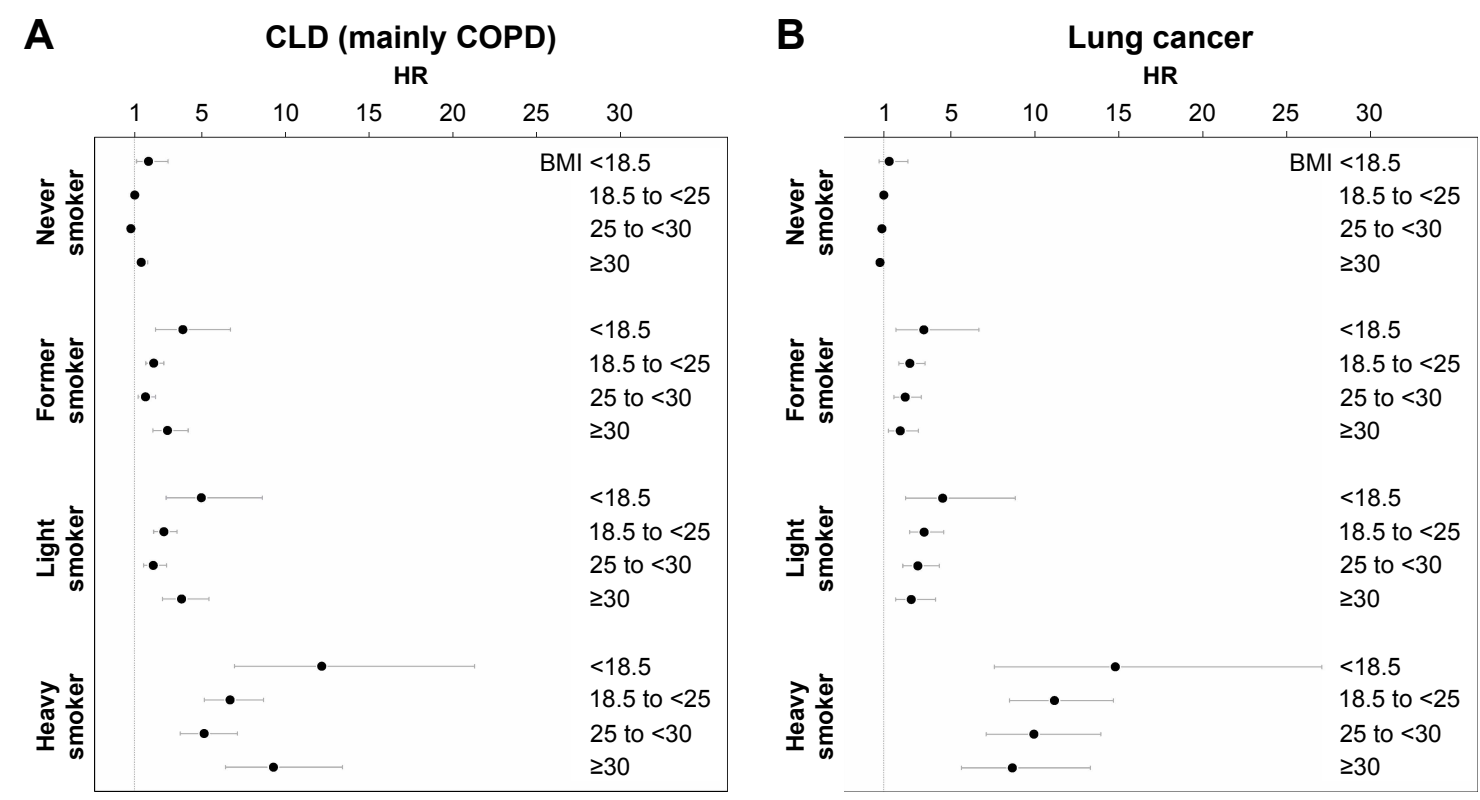

Figure I Relative* risks of chronic lung disease (A) and lung cancer (B) of BMl categories by smoking status (hazard ratios with $95 \% \mathrm{Cl}$ ).

Notes: *Reference population are normal weight (BMI 18.5 to $\leq 25 \mathrm{~kg} / \mathrm{m}^{2}$ ) individuals who never smoked; adjusted for age, sex, survey, years of education, marital status, nationality, physical activity, alcohol consumption, and a diet proxy.

Abbreviations: BMI, body mass index; CLD, chronic lung disease; HR, hazard ratio.

is more consistent ${ }^{2,4,5,10-12,18}$ and could be observed in people with preexisting lung disease as well as in individuals with normal lung function at baseline. ${ }^{11,18}$

For both CLD and lung cancer, the respective associations between BMI and mortality risk were strikingly similar in all considered smoking status groups. This corroborates other findings, suggesting that the increased CLD risk in underweight individuals is not due to smoking. ${ }^{3,7,8,11}$ Partially at odds was a study with a general population sample from Italy, showing that the increased risk of overweight/obesity for COPD was quite independent of smoking status, while in underweight individuals, there was only an increased risk in current and former smokers but not in never smokers. ${ }^{12}$ Patients with CLD have an increased energy demand. However, this only holds true for the most progressed form of the disease, and it is very unlikely that such individuals were included in our study. In our population, for both outcomes - CLD and lung cancer - underweight and heavy smoking combined constituted a high risk of death (HR of about 15). Generally, somewhat lower relative risks for this combination were reported. ${ }^{8,12}$

Our study has limitations. The single cross-sectional assessment of risk factors (smoking, BMI) at baseline precludes conclusions regarding causality and temporal sequence. We had data only on mortality and no information on CLD or cancer incidence. The exposure measurement in our study was crude and, for some variables, not uniform as we pooled different surveys to obtain a sufficient number of deaths. Measurements were only assessed once at baseline precluding the consideration of, for example, smoking status over time. We had no information on objectively measurable mediators of the association between smoking/BMI and death. ${ }^{19,20}$ In fact, besides forced expiratory volume, resting heart rate, arm circumference, and other clinical parameters may blunt the impact of BMI on mortality when used in a joint model. ${ }^{19}$ The reliability of CLD on death certificates has been questioned. ${ }^{14}$ As a consequence, a dilution of the associations might be expected. The close similarity of CLD and lung cancer mortality patterns in our study, however, does not support this concern. We did not consider that causes of death risk competition could vary depending on the length of follow-up time. ${ }^{21}$ Younger individuals (eg, aged $<40$ years) did not notably contribute to CLD death. However, as any limitation of the age range would have been somewhat arbitrary, we decided to analyze the entire available age range.

In conclusion, underweight (for CLD and lung cancer) and obesity (for CLD only) were associated with an increased mortality risk independent of smoking status. Further research is required in order to evaluate the causality of this association and to identify the potential for prevention interventions. Our results stress the need to intensify smoking cessation efforts in people with low or high BMI and - even more importantly - to reinforce public health measures aimed at preventing smoking onset at an early stage of life. 


\section{Acknowledgments}

We thank the Swiss Federal Statistical Office for providing mortality and census data and for the support, which made the Swiss National Cohort (SNC) and this study possible. This study was supported by the Swiss National Science Foundation (grant nos 3347CO-108806, 33CS30_134273, and 33CS30_148415). The SNC was supported by the Swiss National Science Foundation (grant nos 3347CO-108806, 33CS30_134273, and 33CS30_148415). The members of the Swiss National Cohort Study Group are Matthias Egger (Chairman of the Executive Board), Adrian Spoerri and Marcel Zwahlen (all Bern), Milo Puhan (Chairman of the Scientific Board), Matthias Bopp (both Zurich), Nino Künzli (Basel), Michel Oris (Geneva), and Murielle Bochud (Lausanne).

\section{Author contributions}

$\mathrm{DF}$ and $\mathrm{MB}$ conceived the study and assisted in data analysis, design of figures and tables, and writing. SRH and MK mainly performed statistical analyses and designed tables and figures. SRH and MK assisted in writing the Materials and Methods section. MB and DF added the important background knowledge and improved the manuscript by repeated readings and rephrasing as well as critical discussions of the intellectual content. All authors critically reviewed the paper and contributed to the final version of the manuscript.

\section{Disclosure}

The authors report no conflicts of interest in this work.

\section{References}

1. Lozano R, Naghavi M, Foreman K, et al. Global and regional mortality from 235 causes of death for 20 age groups in 1990 and 2010: a systematic analysis for the Global Burden of Disease Study 2010. Lancet. 2012;380(9859):2095-2128.

2. Guo Y, Zhang T, Wang Z, et al. Body mass index and mortality in chronic obstructive pulmonary disease: a dose-response meta-analysis. Medicine (Baltimore). 2016;95(28):e4225.

3. Bridevaux PO, Probst-Hensch NM, Schindler C, et al. Prevalence of airflow obstruction in smokers and never-smokers in Switzerland. Eur Respir J. 2010;36(6):1259-1269.
4. Cao C, Wang R, Wang J, et al. Body mass index and mortality in chronic obstructive pulmonary disease: a meta-analysis. PLoS One. 2012;7(8):e43892.

5. Divo MJ, Cabrera C, Casanova C, et al. Comorbidity distribution, clinical expression and survival in COPD patients with different body mass index. Chronic Obstr Pulm Dis. 2014;1(2):229-238.

6. Smith L, Brinton LA, Spitz MR, et al. Body mass index and risk of lung cancer among never, former, and current smokers. J Natl Cancer Inst. 2012;104(10):778-789.

7. Yang Y, Dong J, Sun K, et al. Obesity and incidence of lung cancer: a meta-analysis. Int J Cancer. 2013;132(5):1162-1169.

8. El-Zein M, Parent ME, Nicolau B, Koushik A, Siemiatycki J, Rousseau MC. Body mass index, lifetime smoking intensity and lung cancer risk. Int J Cancer. 2013;133(7):1721-1731.

9. Duan P, Hu C, Quan C, et al. Body mass index and risk of lung cancer: systematic review and dose-response meta-analysis. Sci Rep. 2015;5: 16938 .

10. The Global BMI Mortality Collaboration, Di Angelantonio E, Bhupathiraju SHN, Wormser D, et al. Body-mass index and all-cause mortality: individual-participant-data meta-analysis of 239 prospective studies in four continents. Lancet. 2016;388(10046):776-786.

11. Yang L, Zhou M, Smith M, et al. Body mass index and chronic obstructive pulmonary disease-related mortality: a nationally representative prospective study of 220,000 men in China. Int J Epidemiol. 2010; 39(4):1027-1036.

12. Cazzola M, Calzetta L, Lauro D, et al. Asthma and COPD in an Italian adult population: role of BMI considering the smoking habit. Respir Med. 2013;107(9):1417-1422.

13. Roh L, Braun J, Chiolero A, Bopp M, Rohrmann S, Faeh D; Swiss National Cohort Study Group. Mortality risk associated with underweight: a census-linked cohort of 31,578 individuals with up to 32 years of follow-up. BMC Public Health. 2014;14(1):371.

14. Jensen HH, Godtfredsen NS, Lange P, Vestbo J. Potential misclassification of causes of death from COPD. Eur Respir J. 2006;28(4): 781-785.

15. Ahmad OB, Boschi-pinto C, Lopez AD. Age standardization of rates: a new WHO standard. GPE Discuss Pap Ser. 2001;31:1-14.

16. Fine JP, Gray RJ. A proportional hazards model for the subdistribution of a competing risk. J Am Stat Assoc. 1999;94(446):496-509.

17. Lau B, Cole SR, Gange SJ. Competing risk regression models for epidemiologic data. Am J Epidemiol. 2009;170(2):244-256.

18. Zhou Y, Wang D, Liu S, et al. The association between BMI and COPD: the results of two population-based Studies in Guangzhou, China. COPD. 2013;10(5):567-572.

19. Puddu PE, Menotti A, Tolonen H, Nedeljkovic S, Kafatos AG. Determinants of 40-year all-cause mortality in the European cohorts of the Seven Countries Study. Eur J Epidemiol. 2011;26(8):595-608.

20. Menotti A, Puddu PE, Maiani G, Catasta G. Cardiovascular and other causes of death as a function of lifestyle habits in a quasi extinct middleaged male population. A 50-year follow-up study. Int J Cardiol. 2016; 210:173-178.

21. Puddu PE, Piras P, Menotti A. Competing risks and lifetime coronary heart disease incidence during 50 years of follow-up. Int J Cardiol. 2016; 219:79-83.
International Journal of COPD

\section{Publish your work in this journal}

The International Journal of COPD is an international, peer-reviewed journal of therapeutics and pharmacology focusing on concise rapid reporting of clinical studies and reviews in COPD. Special focus is given to the pathophysiological processes underlying the disease, intervention programs, patient focused education, and self management protocols.

\section{Dovepress}

This journal is indexed on PubMed Central, MedLine and CAS. The manuscript management system is completely online and includes a very quick and fair peer-review system, which is all easy to use. Visit http://www.dovepress.com/testimonials.php to read real quotes from published authors. 